\title{
Ash \& Pulverized Coal Deposition in Combustors \& Gasifiers
}

\author{
Quarterly Report \\ July 1 - September 30, 1997
}

\author{
By \\ Goodarz Ahmadi
}

Work Performed Under Contract No.: DE-FG22-94PC94213

\author{
For \\ U.S. Department of Energy \\ Office of Fossil Energy \\ Federal Energy Technology Center \\ P.O. Box 880 \\ Morgantown, West Virginia 26507-0880 \\ By \\ Department of Mechanical and \\ Aeronautical Engineering \\ Clarkson University
}




\section{Disclaimer}

This report was prepared as an account of work sponsored by an agency of the United States Government. Neither the United States Government nor any agency thereof, nor any of their employees, makes any warranty, express or implied, or assumes any legal liability or responsibility for the accuracy, completeness, or usefulness of any information, apparatus, product, or process disclosed, or represents that its use would not infringe privately owned rights. Reference herein to any specific commercial product, process, or service by trade

name, trademark, manufacturer, or otherwise does not necessarily constitute or imply its endorsement, recommendation, or favoring by the United States Government or any agency thereof. The views and opinions of authors expressed herein do not necessarily state or reflect those of the United States Government or any agency thereof. 
DOE DE-FG22-94PC-94213

\title{
Quarterly Technical Progress Report
}

(July 1, 1997 to September 30, 1997)

\section{ASH \& PULVERIZED COAL DEPOSITION IN COMBUSTORS \& GASIFIERS}

Grant Number: DE-FG22-94PC-94213--13

\author{
Goodarz Ahmadi \\ Department of Mechanical and Aeronautical Engineering \\ Clarkson University
}

Submitted to:

U.S. Department of Energy

Federal Energy Technology Center

Pittsburgh, PA

Attention:

Dr. Norman Holcombe

Dr. Rodney A. Geisbrecht

Technical Project Officers

Dr. Eric T. Bell

Program Administrator 


\section{ASH \& PULVERIZED COAL DEPOSITION IN COMBUSTORS \& GASIFIERS}

Grant Number: DE-FG22-94PC-94213

Project Period: September 1, 1994 to August 31, 1998

Contract Recipient: Clarkson University

Project Principal Investigator: Goodarz Ahmadi

DOE Project Officer: Dr. Norman Holcombe and Dr. Rodney A. Geisbrecht

DOE Program Administrator: Dr. Eric T. Bell

\section{SUMMARY}

Further progress in achieving the objectives of the project was made in the period of July 1 to September 30, 1997. The direct numerical simulation of particle removal process in turbulent gas flows was continued. Variations of vorticity contours which are averaged over a short time duration are studied. It is shown that the near wall vortices profoundly affect the particle removal process in turbulent boundary layer flows.

The sublayer model for evaluating the particle deposition in turbulent flows was extended to include the effect of particle rebound. A new more advance flow model for the near wall vortices is also used in these analysis. Sample particle trajectories are obtained and discussed.

Experimental data for transport and deposition of fibrous particles in the aerosol wind tunnel was obtained. The measured deposition velocity is compared with the empirical correlation and the available data and discussed.

Particle resuspension process in turbulent flows are studied. The model is compared with the experimental data. It is shown that when the effects of the near wall flow structure, as well as the surface roughness are included the model agrees with the available experimental data. 


\section{OBJECTIVE AND SIGNIFICANCE}

In this section the objective of the project and its significance to the fossil energy program are outlined.

\section{Objectives}

The general goal of this project is to provide a fundamental understanding of deposition processes of flyash and pulverized coal particles in coal combustors and coal gasifiers. The specific objectives are:

1) To provide a fundamental understanding of deposition mechanisms for coal and ash particles via digital simulations of turbulent flow conditions in a coal combustor and/or gasifier and the Lagrangian particle trajectory analysis.

2) To develop a semi-analytical model for wall deposition rate of coal and flyash particles in complex flow and thermal conditions of coal combustors and gasifiers.

3) To assess the relative significance of turbulent dispersion, Brownian diffusion, thermophoretic, electrostatic and surface forces, as well as particle collision and agglomeration under different conditions.

4) To assess the significant effects of nonsphericity of coal and ash particles on their transport and wall deposition processes.

5) To provide a detail understanding of wall deposition mechanisms for relatively compact, as well as elongated flyash and pulverized coal particles via a direct numerical simulation of near-wall turbulent flows.

6) To experimentally verify the validity of the simulation and analytical results for deposition rates of flyash and pulverized coal particles in the size range of 2 to 100 $\mu \mathrm{m}$ in the upgraded MAE Aerosol Wind Tunnel.

\section{Significance to Fossil Energy Program}

Transport and deposition of particles play a critical role in operation, efficiency, safety and maintenance of coal combustors and gasifiers. Turbulent mixing of pulverized coal significantly affects the efficiency of combustion, pyrolysis and gasification processes. Deposition of flyash and other particles on the wall leads to the formation of coal slag. Corrosion by coal slag is a serious problem in coal-gasification and combustion systems. Presence of particulate contaminant in the combustion product is also a major source of air pollution in coal energy systems.

No completely satisfactory model describing the motion of a coal or ash particle in the highly transient turbulent flow and thermal conditions in coal combustors and gasifiers exists. More importantly, the controlling mechanisms for deposition of particles on surfaces in a turbulent stream with strong temperature gradients are not 
fully understood. Without such an adequate understanding, providing mitigation measures against slag formation and/or improving the efficiency of coal combustors are not possible.

The general goal of this research is to provide a fundamental understanding of transport and deposition mechanisms of ash and pulverized coal particles in complex turbulent flow conditions in a coal-fired combustor or in a coal gasifier. The other main objective is to develop an accurate computational model for simulating motions of ash, pulverized coal, and soot particles in complex geometries of coal (gas turbine) combustors and gasifiers. Availability of these tool and knowledge base will be indispensable for developing an environmentally acceptable coal energy system.

\section{PROGRESS REPORT}

This section outlines the progress made in the period of July 1 to September 30, 1997 in accomplishing the tasks of the project. We have made considerable progress in modeling the particle transport, deposition and resuspension processes in turbulent gas flows, and the experimental study of deposition of nonspherical particles. This quarterly report describes our new findings for particle removal and particle transport and deposition in turbulent recirculating flow fields. In addition, the progress made in direct digital simulation of particle removal in duct flows is described.

\section{COMPUTATIONAL MODELING}

In the earlier reports, we have described the simulation of the gas flow velocity field in complex passages with the use of the STARPIC-RATE computer code that makes use of an advanced anisotropic turbulence model. The particle equation of motion which includes the Stokes drag, the turbulence dispersion effects, the lift force, as well as, the Brownian effects was also used in the simulation. The instantaneous turbulence fluctuations are simulated as an anisotropic continuous Gaussian random vector process. The computational model have been tested earlier for several cases and its accuracy was verified. Studies concerning dispersion and deposition from a point source of particles in a turbulent air flow and deposition from uniform concentration in a circular cylindrical duct and in recirculating flow region were studied before. The details of flow in a duct using a direct numerical simulation procedure and the corresponding particle resuspension are being studied. A summary of the progress made is presented in this section.

\section{Direct Numerical Simulation of Particle Resuspension}

To provide a fundamental understanding of particle resuspension process in turbulent flows, a direct numerical simulation of Navier-Stokes equation was performed. The Navier-Stokes equation is solved directly using a pseudo-spectral computational scheme. The computational grid and the numerical procedure used was outlined in the earlier reports. The velocity vector fields at different times and different planes and the

equation governing the motion of particles were presented in the last report. The structure of near wall flow and the presence of near wall vortices were also discussed. 
A series of computer simulations for particles that were initially distributed (with a statistically uniform distribution) on the xy-plane at a distance of $Y_{0}=1$ wall unit from the upper wall were performed. It was shown that the locations of ejected particles (that reach different levels) form lines with spacings of about 100 to 150 wall units. These variations appeared to be consistent with the available flow visualization results for the streaky structures in the viscous sublayer. It was also observed that these lines shifted to new locations for time duration of 200 to 400 wall units. It was conjectured that the shifting of lines is due to the break-up (or lifting) of vortices and formation of new ones at other locations as time progresses. Those results suggested that the near wall streamwise structure (coherent vortices) plays a dominant role in the particle entrainment process.
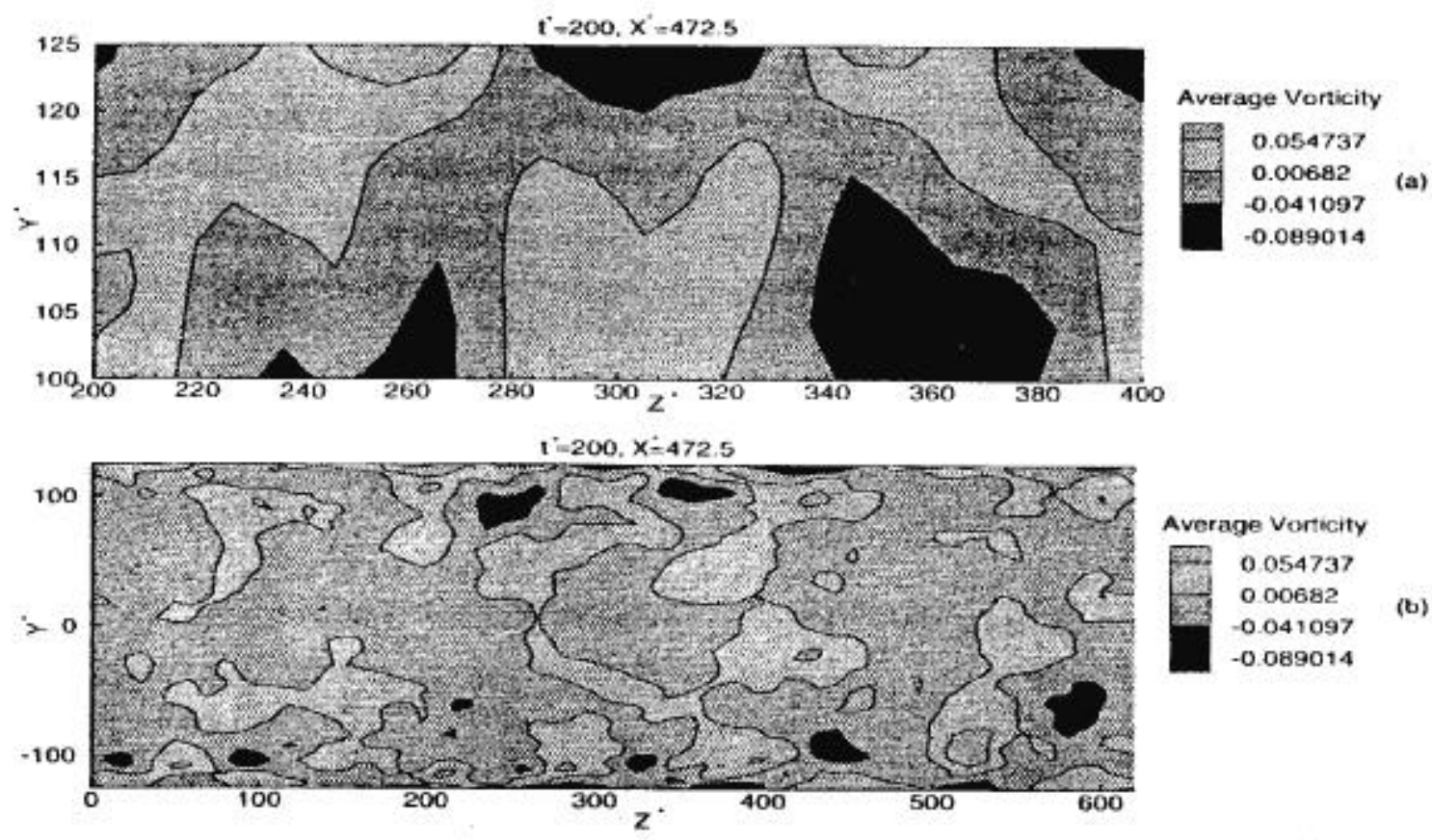

Figure 1. Temporal average of iso-vorticity contours in the yz-plane for $0<t^{+}<200$.

To further clarify the observed pattern of particle motions in the near wall eddies, the temporarily averaged iso-vorticity contour plots in the plane perpendicular to the flow direction are evaluated and the results are shown in Figures 1-3. In these figures, the temporal averaging were carried out, respectively, for time duration of $0<\mathrm{t}^{+}<200$, $200<\mathrm{t}^{+}<400$ and $400<\mathrm{tP}^{+}<600$. Figures 1a, 2a, and 3a show the close-ups of the central region near the upper wall, while Figures $1 b, 2 b$, and $3 b$ show the entire channel section. Figures 1 and 3 show a roughly periodic pairing of (time averaged) counter rotating vortices with approximately similar strength. Figure 2 , however, shows a more distorted picture. These patterns are consistent with the rather distinct line up of particle position in Figures 4 and 6 and the clutter observed in figure 5 of the previous report. Furthermore, the positions of the lines in Figures 4-6 of the last quarterly report are also in good agreement with the regions of small vorticity between two counter rotating vortices near the wall in Figures 1-3. For example, the line at $z^{+}=$ 275 in figure 4 (of last report) corresponds to the gray region (with low vorticity) 
between two counter rotating vortices whose centers are located at $z^{+}$of 255 and 300 , respectively. As noted before, this alignment of particles persists in the time duration of $0<\mathrm{t} P+<600$. Figures 5 and 6 (of last report) showed that this line shifted slightly to about $z^{+}=280$ in the time duration of $200<t P+<600$. Figures 2 and 3 also show that the corresponding region of low vorticity also drift toward $z^{+}=280$. Figure 1 shows the

formation of a region of low vorticity between two counter rotating vortices near $z^{+}=$ 355. This region is distorted and spreads to the range of $305<z^{+}<335$ in the time duration of $200<\mathrm{t}^{+}<400$. Figure 5 (of last report) clearly reflects the scattering of the band of particle position which is comparable to this range.
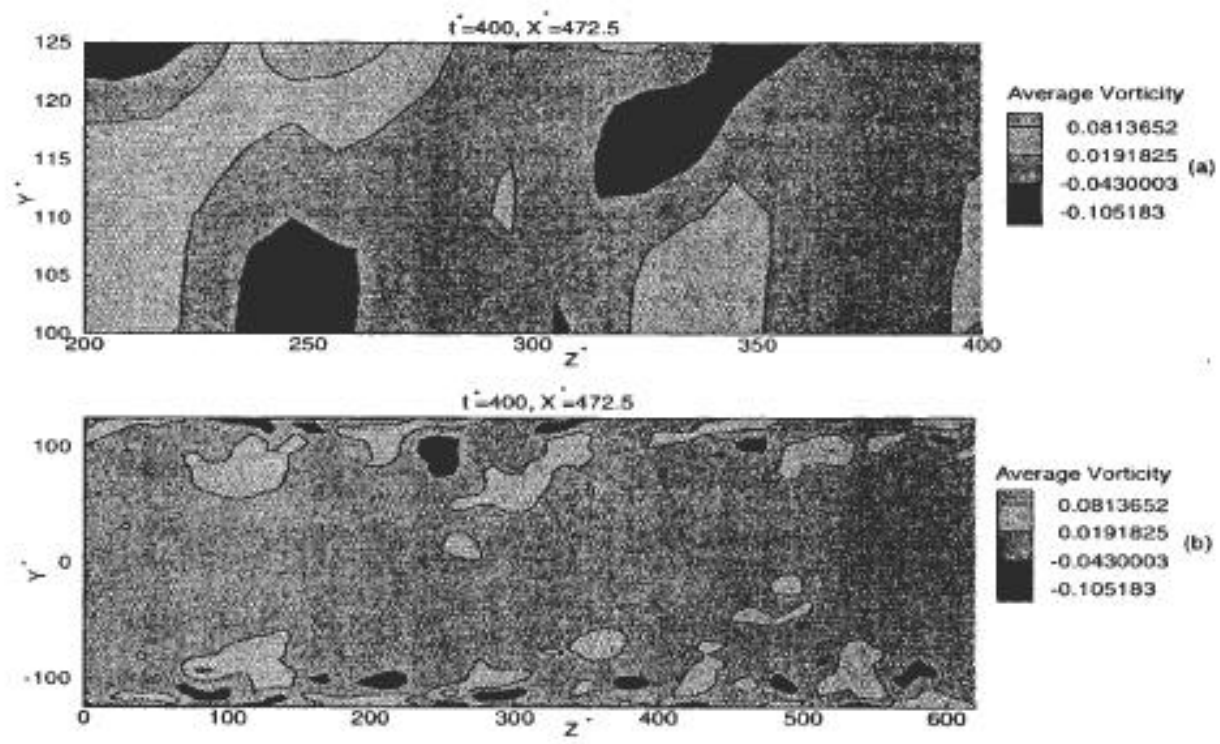

Figure 2. Temporal average of iso-vorticity contours in the yz-plane for $200<t^{+}<400$.
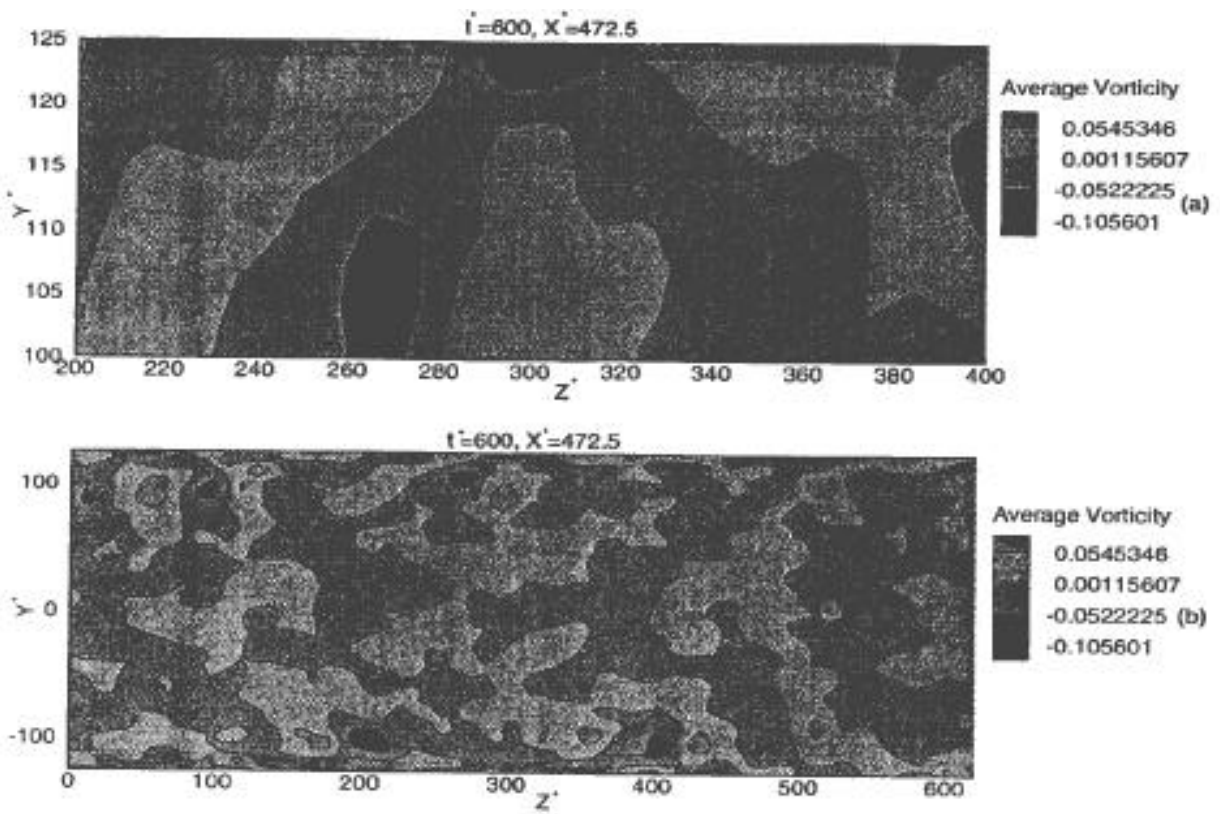

Figure 3. Temporal average of iso-vorticity contours in the yz-plane for $400<t^{+}<600$. 


\section{EXPERIMENTAL STUDY}

The goal of the experimental study is to provide the much needed data base on deposition rates of (generally nonspherical) coal and flyash particles. The experimentation is being performed in the horizontal aerosol wind tunnel and for glass fiber transport and deposition. The geometry of the wind tunnel and the experimental procedure were described in the earlier reports. In the earlier report, the experimental data for the non-dimensional deposition velocity versus the non-dimensional equivalent particle relaxation time, $\tau_{\mathrm{eq}}{ }^{+}$(based on the orientation averaged resistance) were presented. Use of the $\tau_{\text {eq }}{ }^{+} \mathrm{N}$-scaling clearly shows the significant increase of the deposition velocity with aspect ratio of the fiber. This observation is as expected because the increase in aspect ratio increases the wall capture efficiency by the interception mechanism. The experimental results for the deposition rates of cylindrical glass fibers with a minimum diameter of was $5 \mu \mathrm{m}$ using $\tau_{\mathrm{vol}}{ }^{+} \mathrm{N}$-scaling are described in this section.

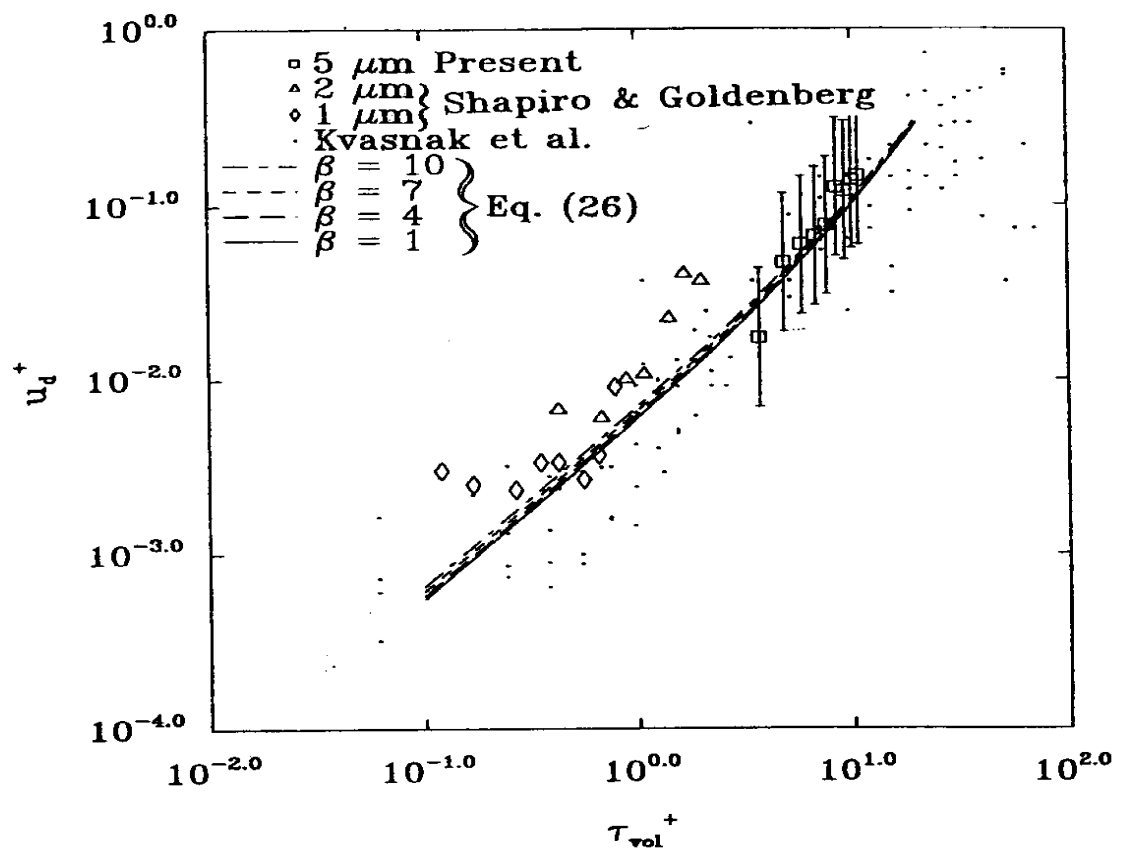

Figure 4. Comparison of the measured deposition velocity of glass fibers in term of equivalent volume relaxation time.

Figure 4 shows the non-dimensional deposition velocity $\mathrm{ud}^{+}$for $5: \mathrm{m}$ glass fibers versus the non-dimensional equivalent volume spherical particle relaxation time. The data of Shapiro and Goldenberg (1993), the data of Kvasnak et al. (1993) for glass spheres and the predictions of empirical equation for different values of $\beta$ are shown in figure 4 for comparison. It is observed that the present data for $5: \mathrm{m}$ glass fibers are in reasonable agreement with the data of Shapiro and Goldenberg (1993) for 1 and $2: \mathrm{m}$ fibers. It is observed that the predictions of the empirical equation for fibers and spherical particles are in reasonable agreement with the experimental data. Furthermore, for a fixed $\tau^{+}$vol (i.e. a fixed particle volume), the deposition rate 
increases only slightly with aspect ratio. As expected, the increasing trend of the deposition velocity with $\tau_{\mathrm{vol}}{ }^{+}$is clearly observed from figure 4 .

\section{SUBLAYER MODEL FOR PARTICLE DEPOSITION}

The importance of streamwise coherent vortices in the turbulent shear flows on particle deposition and removal processes was noted in our earlier and present reports. A simplified sublayer flow model is being developed to analyze particle deposition and rebound form surfaces. The present study is concerned with particle motions in the near wall vortices and the turbulent deposition process. The simulations of Ounis et al. (1991) showed that the streamwise vortices persist for a long duration of time (about 1000 wall units) compared with the characteristic turn around time of these vortices. Due to the prolonged persistence of these vortices, a stationary picture is assumed in the present study. The velocity perturbation in the streamwise direction, which does not directly affect the particle deposition process, is also ignored. To facilitate the analysis, an approximate analytical expression for the flow field was described in the earlier reports.

The equations for particle motion in the turbulence near-wall vortices were described at length by Fan and Ahmadi (1993 and 1994). In these references, the Stokes drag and the Saffman lift force (Saffman, 1965 and 1968) acting on a particle were used in the analyses. In the present study, the lift force induced by the flow shear in the streamwise direction is also included. In contrast to previous works, however, a complete form for the lift force as given by Harper and Chang (1968) is used.

As noted before, the main objective of this work is to provide an understanding of motions of aerosol particles in the shear layer vortices including the rebound effect. Due to the symmetry of the flow field with respect to the centerline $(z=0)$, only the particle trajectories in the positive $z$ region are analyzed. A friction velocity $u^{*}=0.3$

$\mathrm{m} / \mathrm{sec}$ is considered, and the values of $\mu=1.84 \times 10^{-5} \mathrm{~kg} / \mathrm{m} \mathrm{sec}$ and $v=1.502 \times 10^{-5}$ $\mathrm{m}^{2} / \mathrm{sec}$ for air at $15^{\circ} \mathrm{C}$ are used.

Dahneke (1971) suggested that the rebound be accounted for by introducing the surface potential energy. The balance of energy before and after the impact, as described by Friedlander (1977) is used for evaluating the critical approach velocity for the limit of adhesion and the corresponding rebound velocity. The velocity field in the near wall coherent eddies were described in the earlier report. It is assumed that the particles start their flights at a distance of 12 wall unit from the wall. The initial particle velocity is given by

$$
\mathbf{u}_{0}^{P_{+}}=\mathbf{u}_{0}^{f}+\tau^{+} g^{+}
$$

where $\mathbf{u}_{0}{ }^{f}$ is the fluid velocity at the initial position of the particle, and a superscript + stands for a nondimensionalized quantity with use of kinematic viscosity $v$ and shear velocity $u^{*}$. The particle equation of motion are solved numerically using an Euler's 
backward method. In the course of flight, a particle may either be intercepted by the wall or being carried back to $\mathrm{y}^{+}=12$ without encountering the wall. At the moment a particle hits the wall (i.e., $\mathrm{y}^{+}=\mathrm{d}^{+} / 2$ ), the particle wall interaction equation is used to determine the following state of motion. If the absolute value of the particle $y$ component velocity is greater than the critical velocity, the rebound velocity is valuated, and the numerical integration continues; otherwise, the particle is assumed to stick to the wall. Once a particle is carried back to $\mathrm{y}^{+}=12$, it is assumed that the particle leaves the flow region of interest and does not deposit on the wall.

The yz -projections of some sample particle trajectories are displayed in Figures 5-12. Particle-to-fluid density ratios of 870 and 1820, coefficients of restitution of 0.6 and 0.7 and various particle diameters are considered. The distance between a trajectory and the centerline at 12 wall unit from the wall is denoted by $z_{12}{ }^{+}$. It is observed that, among the particle trajectories, there is a specific trajectory which separates those for which the particles are intercepted by the wall and the ones for which a contact with the wall does not occur. This particular trajectory is termed the limiting trajectory (LT). The value of $\mathrm{z}_{12}{ }^{+}$for the limiting trajectory is denoted by $\mathrm{z}_{\mathrm{L} 12}$ ${ }^{+}$(i.e., $\mathrm{ZL}_{\mathrm{L} 12}{ }^{+}$is the supremum of the set of $\mathrm{z}_{12}$ for which the particles deposit on the wall). In Figures 5 - 12, parameter $R$ identifies the initial particle location ( $z$ coordinate) relative to that of the limiting trajectory (i.e., $R=z_{12}{ }^{+} / \mathrm{z}_{\mathrm{L} 12}{ }^{+}$).

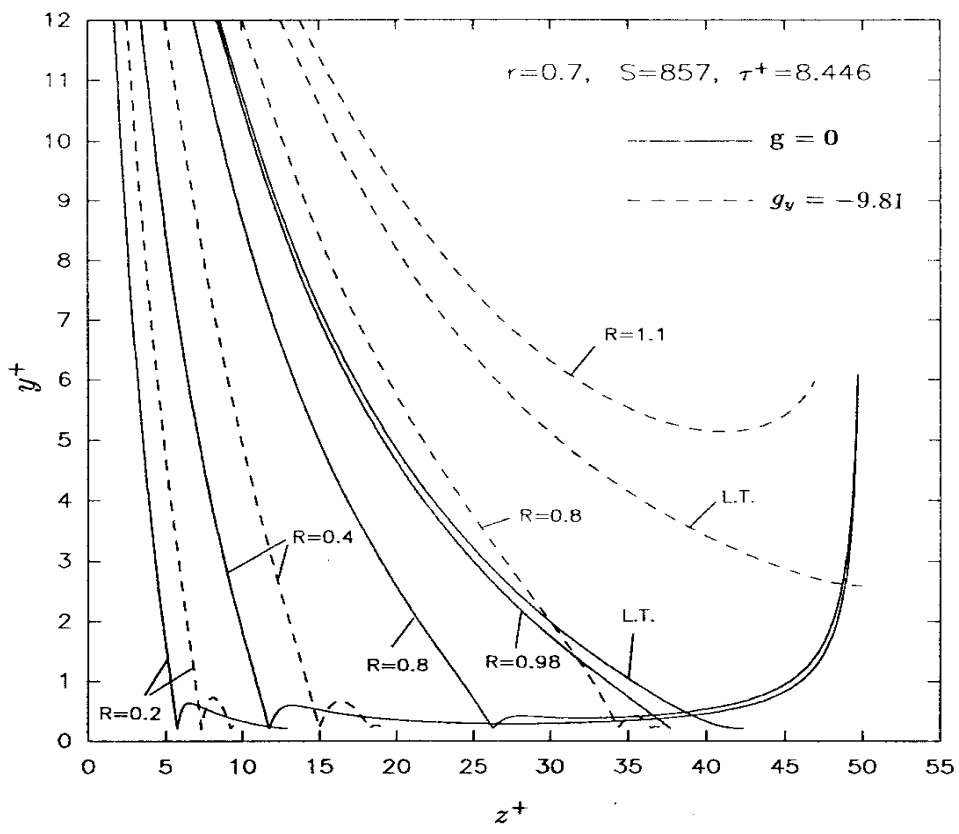

Figure 5. Sample particle trajectories for $r=0.7, S=857, \tau^{+}=8.446$.

Figure 5 shows the particle trajectories for $r=0.7, S=857$ and $d=21: \mathrm{m}\left(\tau^{+}=\right.$ 8.446). The solid lines correspond to those for which the gravitational force is not included. It is observed that, in the absence of gravity, the limiting trajectory terminates at about $\mathrm{y}^{+}=\mathrm{d}^{+} / 2$ and $\mathrm{z}^{+}=42$. At this location, the limiting trajectory is parallel to the wall (i.e., $\mathrm{v}^{\mathrm{P}+}=0$ at this point). It worth mentioning that the time a particle takes to 
transport from $\mathrm{y}^{+}=12$ to the wall following this limiting trajectory is about 105 in wall unit. A particle with trajectory very close to the limiting trajectory (e.g., $\mathrm{R}=0.98$ solid line) collides with the wall with a very small angle (i.e., with very low y -component velocity) and stick to it without rebound. It is also observed that a particle with an initial position very close to the centerline (e.g., $R=0.2$ solid line) hits the wall with a rather large angle (with large $\mathrm{v}^{\mathrm{P}+}$ ) and rebounds from the surface. However, these particles are eventually captured by the wall at their second collisions with the wall. It is noticed from the solid lines of Figure 5 that particles originating from certain region between $z^{+}$ $=0$ and $\mathrm{z}_{\mathrm{L} 12}{ }^{+}$escape from the flow region after crossing the limiting trajectory.

The dot-dashed lines of Figure 5 are trajectories of particles under gravitational sedimentation (i.e., $g_{x}=g_{z}=0$ and $g_{y}=-9.81 \mathrm{~m} / \mathrm{sec}^{2}$ ). It is observed that, under the action of gravity, the limiting trajectory (LT) does not terminate at a particle radius away from the wall. Figure 5 shows that the limiting trajectory terminates at $\mathrm{y}^{+}=2$ and $z^{+}=$ 50 where the Stokes drag acting on the particle is balanced by the gravitational force. Figure 5 also shows that the particle rebound pattern under gravity is similar to that in the absence of gravity. However, due to the gravitational force and the larger region bounded by the limiting trajectory, particles under the action of gravity are less likely to escape from the flow region comparing to those in the absence of gravity.

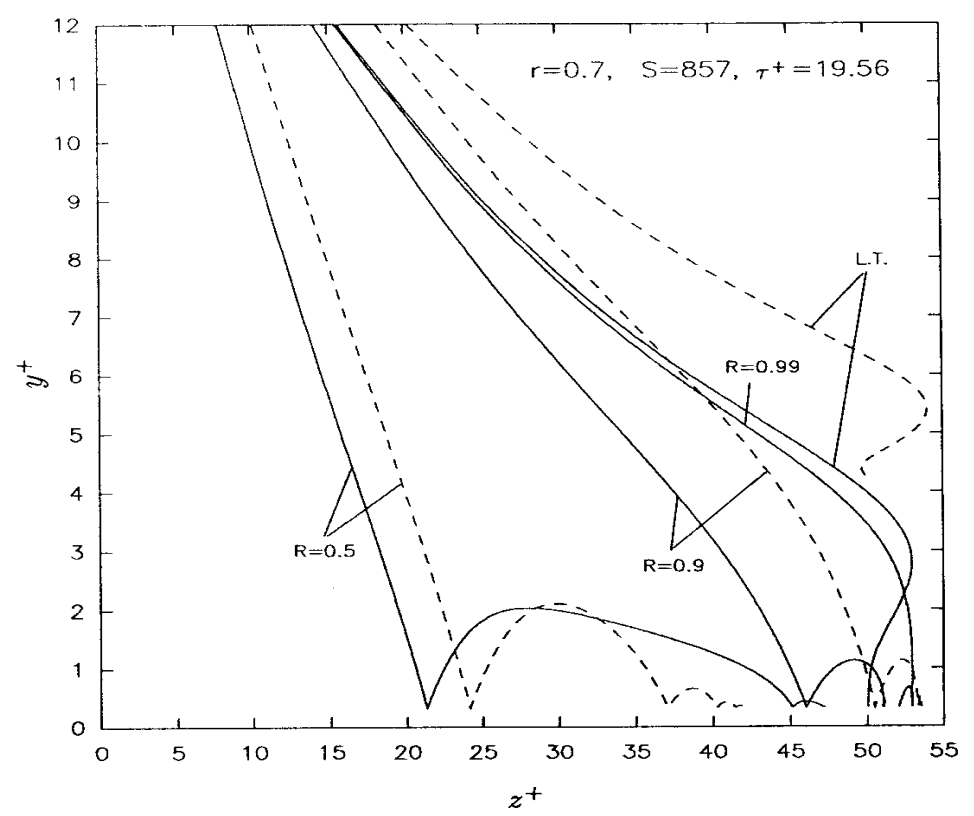

Figure 6. Sample particle trajectories for $r=0.7, S=857, \tau^{+}=19.56$.

For larger diameter, the particle trajectories and the deposition pattern change dramatically as shown in Figure 6. Here, a particle with a diameter of 32 micron is considered. It is noticed that particles of this size, the inertial and the lift forces of which are significant, may penetrate into the neighboring vortex $\left(z^{+}>50\right)$. The solid lines shows sample particle trajectories in the absence of external force field $(\mathbf{g}=0)$. Under such a condition, the limiting trajectory terminates at $\mathrm{y}^{+}=\mathrm{d}^{+} / 2$ and $\mathrm{z}^{+}=50$. 
Several other trajectories with various values of $\mathrm{Z}_{12}{ }^{+}$are also shown in this figure. The rebound pattern is quite different from the one shown in Figure 5. It is noticed that the particle with an initial location $R=0.5$ (solid line) hits the wall at $z^{+}=21.4$ and bounces off. This particle subsequently enters the up-flow region of the vortex (i.e., $25<\mathrm{z}^{+}<50$ ). Instead of being carried away from the wall by the up-flowing fluid motion in this region, it is observed that the particle drifts toward the wall and eventually deposits at $\mathrm{z}^{+}=49$. This behavior may be explained as follows. As the particle being transported toward the wall in the down-sweep region (i.e., $0<\mathrm{z}^{+}<25$ ) and after the collision with the wall, the particle streamwise velocity is larger than that of the local fluid. As a results, a negative $y$-component of the lift force tends to push the particle to the wall. Figure 6 also shows that, in the absence of gravity, all particles considered here are captured by the wall at their second collisions despite their large sizes.

The trajectories of particle under gravitational sedimentation are shown by the dotdashed lines in Figure 6 . The limiting trajectory terminates at the stationary point $y^{+}=$ 4.1 and $z^{+}=50$ at which the drag and the gravitational force balance each other. It is observed that the particle with $\mathrm{R}=0.5$ enters the up-flow region after the first collision with the wall. However, due to the negative y -component left force, the particle then bounces in the up-flow region two times and finally deposits on the wall. Figure 6 also shows that, in the presence of gravitational field, all particles considered are captured by the wall after several collisions with the wall except for the one following the limiting trajectory which stays at $\mathrm{y}^{+}=4.1$ and $\mathrm{z}^{+}=50$.

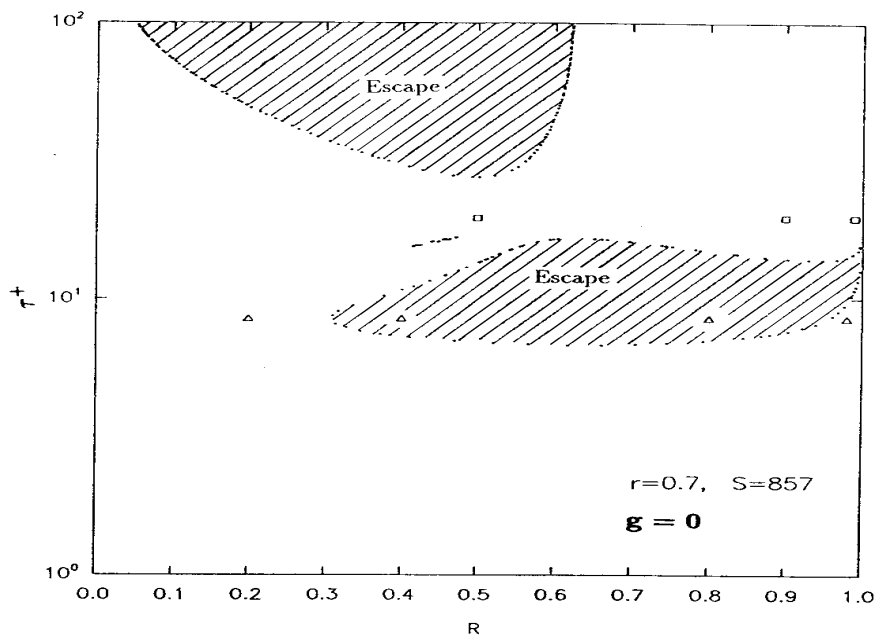

Figure 7. Basins of particle deposition and escape for $r=0.7, S=857, \boldsymbol{g}=0$.

Figure 7 shows the basins of deposition and escape in the parameter space $\left[R, \tau^{+}\right.$ ] for $r=0.7, S=857$ and $d g=0$. Particles with parameters within the hatched areas bounce off the wall and will eventually escape from the flow region. Particles with parameters outside the hatched areas are captured by the wall (either without rebound or after one or several collisional rebounds). The parameters corresponding to the trajectories (for $\mathbf{g}=0$ ) shown in Figures 5 and 6 are displayed in Figure 7 by the 
triangle and the square symbols, respectively. It is noticed that, for $\tau^{+}<6$, all the particles within the limiting trajectory are bound to deposit on the wall. For $6<\tau^{+}<17$, a smaller and a larger island of escape region in the parameter space is observed. For $17<\tau^{+}<27$, Figure 7 shows that all the particle deposit on the wall.

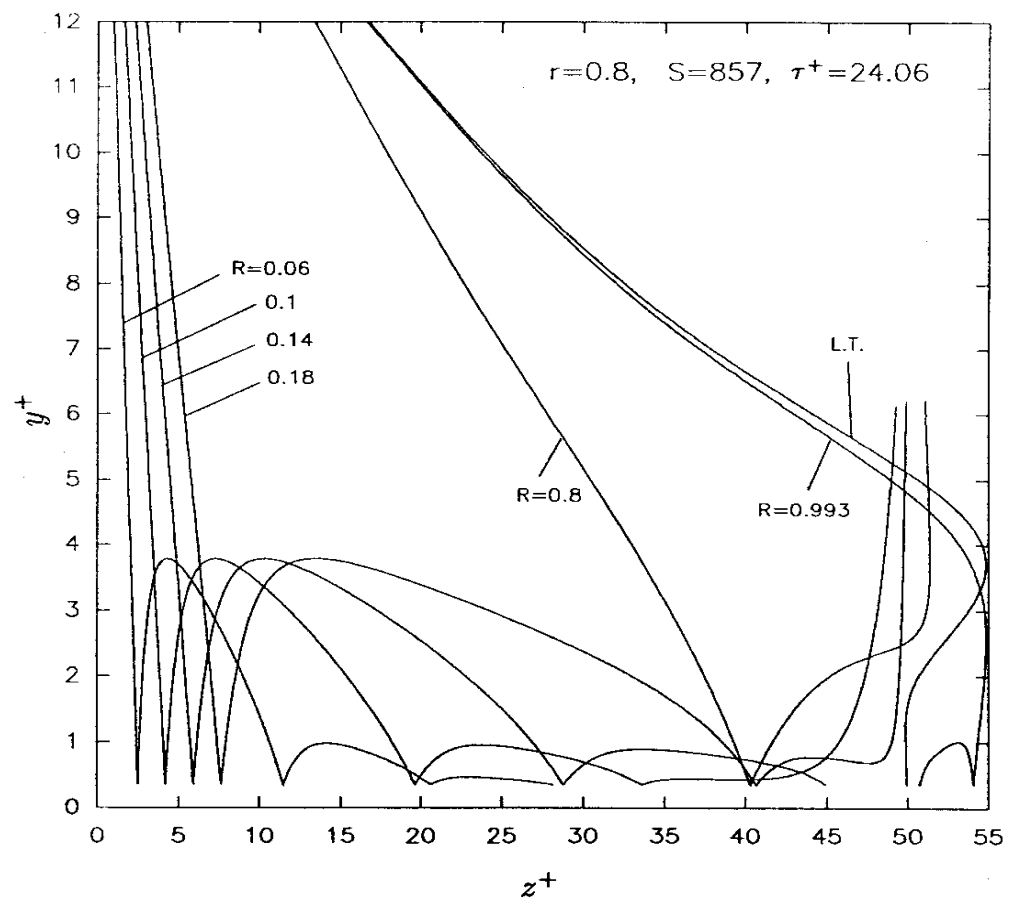

Figure 8. Sample particle trajectories for $r=0.8, S=857, \tau^{+}=24.06, g=0$.

Figure 8 shows several particle trajectories for $r=0.8, S=857, d=35.5: m$, and $\mathbf{g}=0$. Due to the rather elastic nature of particles, some spheres may rebound from the wall twice before sticking to it. The basins of escape and deposition for $r=0.8, S=$ 857 and $\mathbf{g}=0$ in the parameter space are shown in Figure 9. It is observed that the particle motion and the rebound pattern are quite complex. Comparing Figure 9 with Figure 7 shows that, as the particles become more elastic, the two separated regions of escape shown in Figure 7 gradually merge into one large region. Meanwhile, other small islands of escape also emerge. The parameters corresponding to the particle trajectories shown in Figure 8 are displayed on Figure 4b by the small triangles.

Several sample trajectories for $r=0.7, S=1820, d=20.5: \mathrm{m}$ (corresponding to $\tau+=17.1)$ and $d g=0$ are displayed in Figure 10. This figure shows that, between the centerline and $\mathrm{z}^{+}=\mathrm{zL} 12^{+}$, a region of escape occurs. The basins of escape and deposition in the $\left[R, \tau^{+}\right]$space are shown in Figure 11. When compared with Figure 7 , it is observed that the originally separated escape regions are now merged into one large region as the particle-to-fluid density ratio increases. The triangle symbols correspond to the parameters for the trajectories shown in Figure 9. 


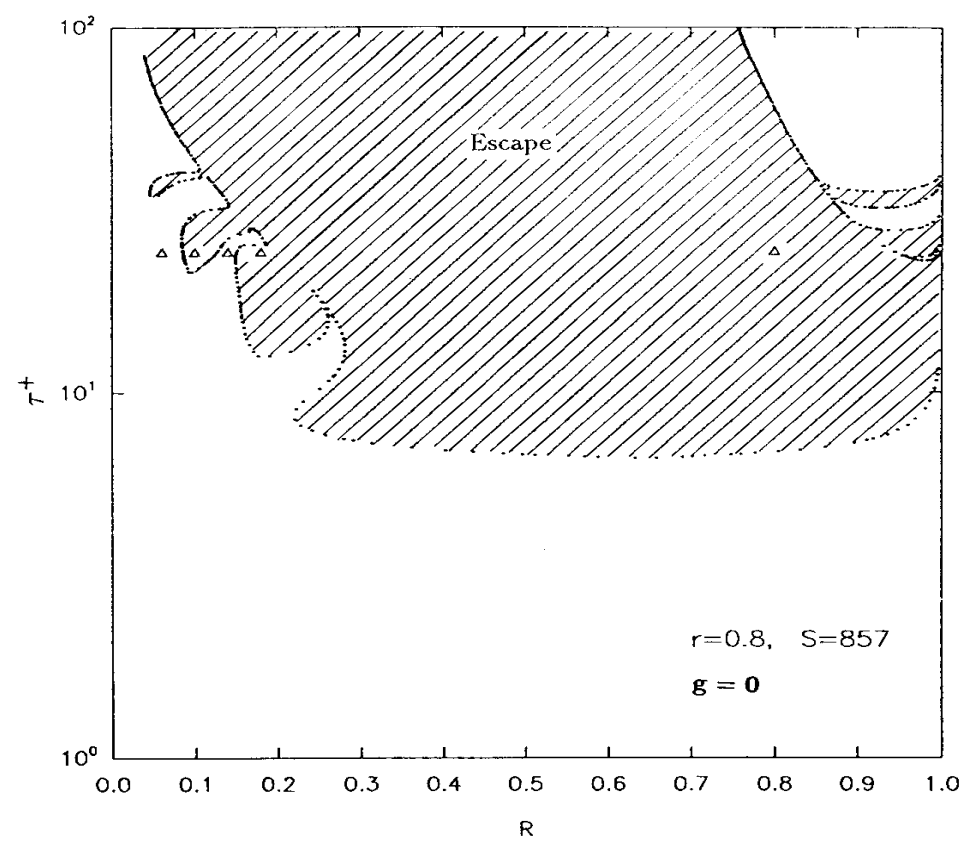

Figure 9. Basins of particle deposition and escape for $r=0.8, S=857, g=0$.

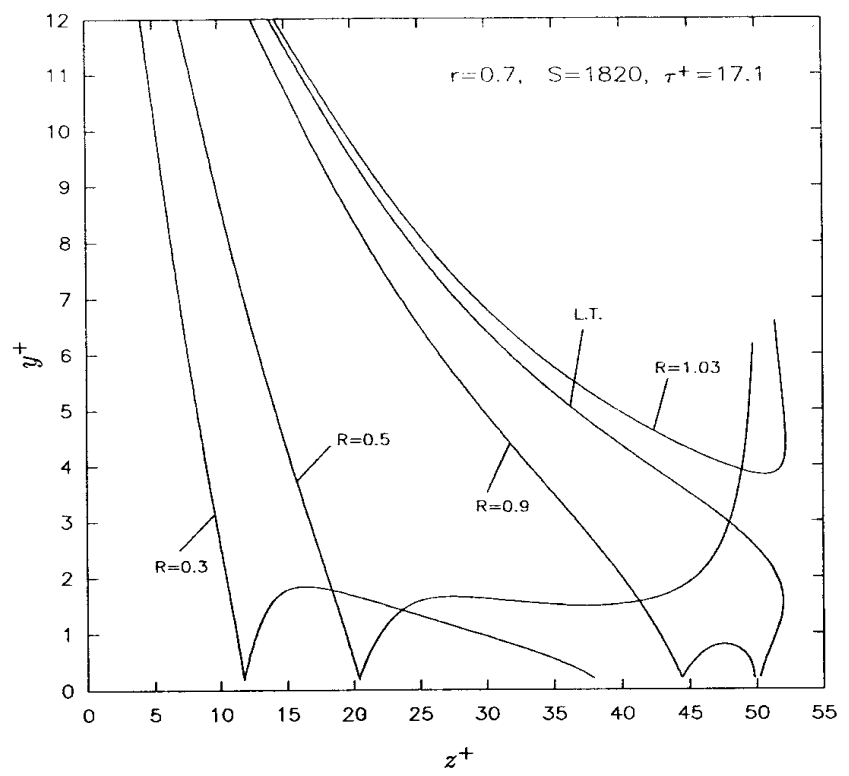

Figure 10. Sample particle trajectories for $r=0.8, S=1820, \tau^{+}=17.1, g=0$. 


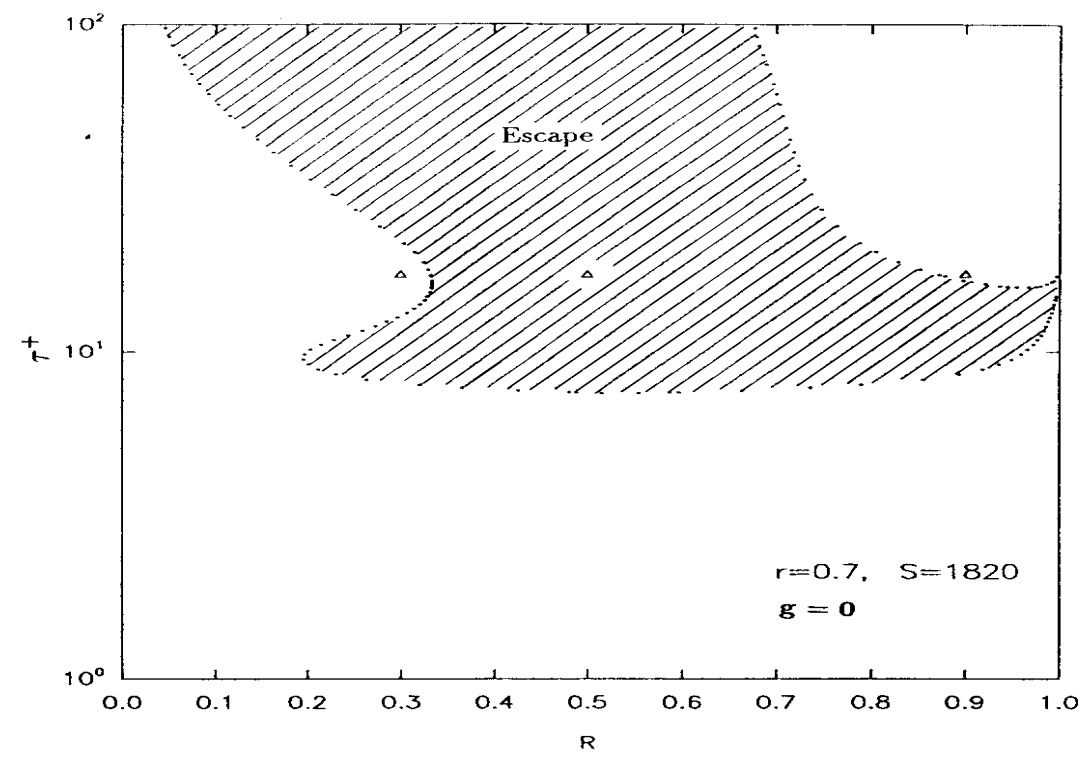

Figure 11. Basins of particle deposition and escape for $r=0.7, S=1820, g=0$.

The regions of escape and deposition for $r=0.8$ and $S=1820$ are shown in Figure 12. For $g_{y}=-9.81 \mathrm{~m} / \mathrm{sec}^{2}$, the parameter-space plot (similar to Figures 7 and 8) shows the escape region around $\tau^{+}=10$ disappears due to the action of gravity. In this case, the corresponding region of escape does not occur until $\tau^{+}>30$.

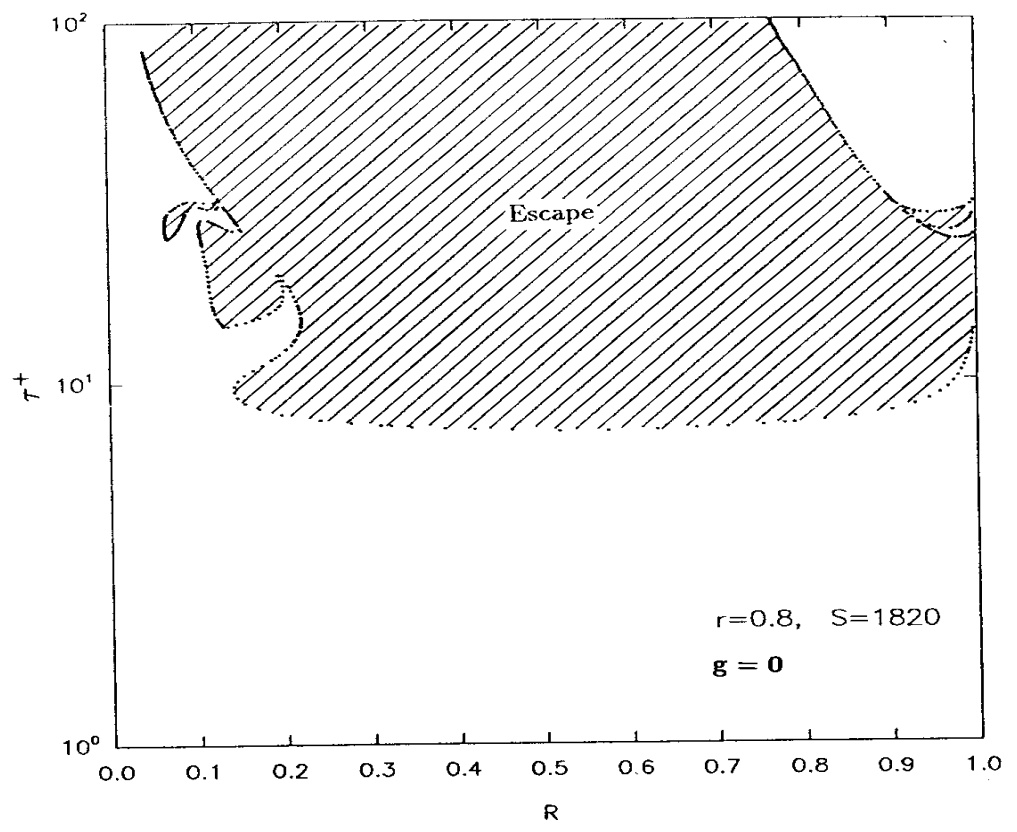

Figure 12. Basins of particle deposition and escape for $r=0.8, S=1820, \boldsymbol{g}=0$.

Figures 5 - 12 show that particles in the shear layer vortices may deposit on the wall or being carried back to $y^{+}=12$ as they are convected by the vortical flow. 
Some particles may deposit on the wall with no rebound or after several rebounds. Particles which are returning back to the $\mathrm{y}^{+}=12$ level either had no encounter with the wall or bounced off from the wall after single or multiple collisions. Wu et al. (1992) identified the particle trajectory that terminates at $\mathrm{y}^{+}=\mathrm{d}^{+} / 2$ and $\mathrm{z}^{+}=\Lambda^{+} / 4$ as the limiting trajectory and estimated the fraction of rebound by examining the probability that the particle impact velocity exceeds the critical velocity at the first particle-wall encounter. The present results show that, in general, the fraction of particle rebound (i.e., the fraction of particles bounded by the limiting trajectory that escape deposition) may not be determined simply by comparing the impact velocity with the critical velocity at a particular collision. It is necessary to trace the particle rebound trajectories for determining the fraction that deposits on the wall (or the fraction that leaves the flow region) with reasonable accuracy.

\section{PARTICLE RESUSPENSION IN TURBULENT FLOWS}

In the previous reports, a flow structure-based model for particle resuspension from rough surfaces in turbulent streams were developed. The effect of surface roughness was included in the analysis. It was assumed that the real area of contact is determined by elastic deformation of asperities and the effect of topographic properties of surfaces were included. The JKR adhesion model was used to analyze the behavior of individual asperities. The theories of rolling and sliding detachment were used and the flow induced resuspension was studied. The effects of the near wall coherent eddies, and turbulence burst/inrush motion were included in the model development. The critical shear velocities needed to detach different size particles from rough surfaces under various conditions were evaluated and discussed. The model predictions were compared with the available experimental data and good agreement was obtained. The results indicated that particle removal from rough surfaces could be achieve by both rolling and sliding mechanism. Spherical particles, however, are more easily dislodged by the rolling motion in comparison with the sliding mechanism.

\section{PARTICLE TRANSPORT AND DEPOSITION IN RECIRCULATING FLOWS}

The mean flow and turbulence intensity fields in a recirculating flow in a twodimensional duct in addition to particle dispersion and deposition patterns were described in earlier quarterly reports. The effect of gravity and its direction was also studied. For small particles, it was shown that the recirculating flow pattern and turbulence dominates the particle deposition rate and the effect of gravity is not as significant. 


\section{PUBLICATIONS}

\section{Journals}

F.G. Fan and G. Ahmadi, "On the Sublayer Model for Turbulent Deposition of Aerosol Particles in the Presence of Gravity and Electric Fields," J. Aerosol Science Technology 21, 49-71 (1994).

M. Massoudi and G. Ahmadi, "Rapid Flow of Granular Materials with Density and Fluctuation Energy Gradients," International Journal of Non-Linear Mechanics $\underline{29}$, 487-492 (1994).

M. Soltani, G. Ahmadi, R.G. Bayer and M.A. Gaynes, "Particle Detachment Mechanisms from Rough Surfaces Under Base Acceleration," J. Adhesion Science Technology $\underline{9}$, 453-473 (1995).

F.G. Fan and G. Ahmadi, "Dispersion of Ellipsoidal Particles in an Isotropic PseudoTurbulent Flow Field," ASME J. Fluid Engineering 117, 154-161 (1995).

S. Abu-Zaid and G. Ahmadi, "A Thermodynamically Consistent Rate-Dependent Model for Turbulent Two-Phase Flows," Int. J. Nonlinear Mech. $\underline{30}$, pp. 509-529 (1995).

J. Cao and G. Ahmadi, "Gas-Particle Two-Phase Turbulent Flow in a Vertical Duct," Int. J. Multiphase Flows 21 , 1203-1228 (1995).

J. Cao, G. Ahmadi and Massoudi, "Gravity Granular Flows Down an Inclined Pumpy Chute," J. Fluid Mechanics $\underline{316}$, 197-221 (1996).

\section{Conferences}

J. Cao, G. Ahmadi and M. Massoudi, "Rapid Granular Flows Down an Inclined Bumpy Chute," 31st Annual Technical Meeting of the Society of Engineering Science, Texas A\&M University, College Station, TX, October 10-12, 1994.

J. Cao and G. Ahmadi, "Turbulent Flow of Two-Phase Gas-Particle Mixture in a Vertical Duct," 31st Annual Technical Meeting of the Society of Engineering Science, Texas A\&M University, College Station, TX, October 10-12, 1994.

M. Soltani and G. Ahmadi, "Particle Removal from Smooth and Rough Surfaces under Substrate Acceleration," 18th Annual Meeting of the Adhesion Society, Hilton Head Island, SC, February 19-22, 1995.

J. Cao and G. Ahmadi, "Gas-Particle Two-Phase Turbulent Flow in a Vertical Duct," Proceedings of the Second International Conference on Multiphase Flow '95 - Kyoto, Vol 2, pp. IF3-31-38, Ed. by A. Serizawa, T. Fukano and J. Bataille, Kyoto, Japan, April 3-7, 1995. 
J. Cao, G. Ahmadi and M. Massoudi, "Gravity Granular Flows Down an Inclined Bumpy Chute with Friction," Proceedings of the Second International Conference on Multiphase Flow '95 - Kyoto, Vol 4, pp. P9-1-7, Ed. by A. Serizawa, T. Fukano and J. Bataille, Kyoto, Japan, April 3-7, 1995.

F.G. Fan and Ahmadi, "A Model for Turbulent Deposition of Ellipsoidal Particles," Proceedings of the Second International Conference on Multiphase Flow '95 - Kyoto, Vol 4, pp. PI-1-7, Ed. by A. Serizawa, T. Fukano and J. Bataille, Kyoto, Japan, April 37, 1995.

G. Ahmadi and J. Cao, "Turbulent Gas-Particle Flows in a Vertical Duct," American Filtration and Separation Society, Annual Technical Conference 95, Nashville, TN, April 23-26, 1995.

G. Ahmadi and W. Kvasnak, "Fiber Deposition Rate in a Horizontal Duct Flow - An Experimental Study," American Filtration and Separation Society, Annual Technical Conference 95, Nashville, TN, April 23-26, 1995.

F.G. Fan and Ahmadi, "Overview of Turbulent Deposition Process - Models Based on Near-Wall Coherent Vortices," The 26th Annual Meeting of the Fine Particle Society, and the 1995 Pharmaceutical Sciences and Technology Conference, Chicago, Illinois, August 22-25, 1995.

W. Kvasnak, G. Ahmadi and K. Elliott "Experimental Study of Granular Flow in a Couette Flow Device," The 26th Annual Meeting of the Fine Particle Society, and the 1995 Pharmaceutical Sciences and Technology Conference, Chicago, Illinois, August 22-25, 1995.

Q. Chen and G. Ahmadi, "Particle Transport and Deposition in Turbulent Pipe Flows," The 26th Annual Meeting of the Fine Particle Society, and the 1995 Pharmaceutical Sciences and Technology Conference, Chicago, Illinois, August 22-25, 1995.

J. Cao and G. Ahmadi, "Computational Modeling of Gas-Particle Flows in Ducts at Various Angle of Inclinations," The 26th Annual Meeting of the Fine Particle Society, and the 1995 Pharmaceutical Sciences and Technology Conference, Chicago, Illinois, August 22-25, 1995.

G. Ahmadi, "Computer Simulation of Particle Deposition in Human Lung," The $26^{\text {th }}$ Annual Meeting of the Fine Particle Society, and the 1995 Pharmaceutical Sciences and Technology Conference, Chicago, Illinois, August 22-25, 1995.

M. Soltani and G. Ahmadi, "A Aerosol Particle Resuspension in a Simulated Turbulent Channel Flow," The 26th Annual Meeting of the Fine Particle Society, and the 1995 Pharmaceutical Sciences and Technology Conference, Chicago, Illinois, August 22-25, 1995. 
W. Kvasnak and G. Ahmadi, "Elongated Particle Dispersion in Homogeneous Turbulent Shear Flows," The 26th Annual Meeting of the Fine Particle Society, and the 1995 Pharmaceutical Sciences and Technology Conference, Chicago, Illinois, August 22-25, 1995.

G. Ahmadi and A. Li, "Computational Simulation of Particle Deposition in the First Lung Bifurcation," Fourteenth Annual Meeting of the American Association for Aerosol Research, AAAR '95, Pittsburgh PA, October 9-13, 1995.

W. Kvasnak, G. Ahmadi and R.B. Suhoke, "Aerosol Particle Concentration Measurements in the Near Wall Region of a Turbulent Channel Flow," Fourteenth Annual Meeting of the American Association for Aerosol Research, AAAR '95, Pittsburgh PA, October 9-13, 1995.

G. Ahmadi and A. Li, "Atmospheric Particle Transport and Deposition Near a Building A Computer Simulation Study," Fourteenth Annual Meeting of the American Association for Aerosol Research, AAAR '95, Pittsburgh PA, October 9-13, 1995.

F.G. Fan and Ahmadi, "Deposition of Ellipsoidal Particles in the Turbulent Near Wall Vortices," Fourteenth Annual Meeting of the American Association for Aerosol Research, AAAR '95, Pittsburgh PA, October 9-13, 1995.

G. Ahmadi, M. Soltani, J.B. McLaughlin and H. Ounis, "Charge Particle Deposition in a Directly Simulated Turbulent Channel Flow," Fourteenth Annual Meeting of the American Association for Aerosol Research, AAAR '95, Pittsburgh PA, October 9-13, 1995.

G. Ahmadi, "Fundamentals of Particle Transport and Deposition in Laminar and Turbulent Flows," Filter Engineering Workshop, Morgantown Energy Technology Center, Morgantown, WV, December 5, 1995.

G. Ahmadi, D. Mei, J. Vanosdol, and D.H. Smith, "Modeling of Dust Deposition in a Filter Vessel with Well-Defined Boundary Conditions," Filter Engineering Workshop, Morgantown Energy Technology Center, Morgantown, WV, December 5, 1995.

G. Ahmadi, "Transport and Deposition of Particles in Turbulent Flows," $19^{\text {th }}$ Annual Meeting of the Adhesion Society, Myrtle Beach, SC, February 18-21, 1996.

G. Ahmadi, "Particle Resuspension Patterns in Turbulent Flows," 19th Annual Meeting of the Adhesion Society, Myrtle Beach, SC, February 18-21, 1996.

M. Soltani, G. Ahmadi and J.B. McLaughlin, "Dispersion and Deposition of Charged Particles in a Directly Simulated Turbulent Channel Flow," $70^{\text {th }}$ colloidal and Surface Science Symposium, American Chemical Society, Clarkson University, Potsdam, New York, June 16-19, 1996. 
G. Ahmadi and D.H. Smith, "Particle Transport and Deposition in Hot-Gas Cleanup Filter Vessels," 70th colloidal and Surface Science Symposium, American Chemical Society, Clarkson University, Potsdam, New York, June 16-19, 1996.

J. Cao and G. Ahmadi, "Solid-Liquid Mixtures Down Inclined Chutes," Proceeding of the 1996 ASME Fluids Engineering Division Summer Meeting, San Diego, CA, July 711, 1996, Vol. 1, FED- Vol. 236, pp. 105-110.

F.G. Fan and Ahmadi, "Brownian Dynamics Simulation of the Motion of Elongated Particles in Turbulent Near-Wall Vortices," Proceeding of the 1996 ASME Fluids Engineering Division Summer Meeting, San Diego, CA, July 7-11, 1996, Vol. 1, FEDVol. 236, pp. 299-304.

M. Soltani, F.G. Fan, G. Ahmadi, and S.C. Hart, "Detachment of Rigid-Link Fibers with Linkage Contact in Turbulent Flows," Proceeding of the 1996 ASME Fluids Engineering Division Summer Meeting, San Diego, CA, July 7-11, 1996, Vol. 1, FED- Vol. 236, pp. 735-741.

D.H. Smith, M. Ferer, V. Powell, and G. Ahmadi, "Determination of Filter Cake Thickness from On-Line Flow Measurements and Gas/Particle Transport Modeling," Advance Coal-Fired Power Systems '96 review Meeting, Morgantown Energy Technology Center, Morgantown, West Virginia, July 16-18, 1996.

G. Ahmadi and P. Nicoletti, "Computational Modeling of Hot-Gas Flows in Filtration System at Tidd," 27th Annual Meeting of the Fine Particle Society, and the 1996 Pharmaceutical Sciences and Technology Conference, Chicago, Illinois, August 6-8, 1996.

G. Ahmadi, D.H. Smith, and T.J. O'Brien, "Particle Transport and Deposition in Hot-Gas Filtration System at Tidd," 27th Annual Meeting of the Fine Particle Society, and the 1996 Pharmaceutical Sciences and Technology Conference, Chicago, Illinois, August 6-8, 1996.

G. Ahmadi, and M. Soltani "Overview of Particle Resuspension in Turbulent Flows," 27th Annual Meeting of the Fine Particle Society, and the 1996 Pharmaceutical Sciences and Technology Conference, Chicago, Illinois, August 6-8, 1996.

G. Ahmadi and D.H. Smith, "Computational Modeling of Particle Transport and Deposition in Hot-Gas Cleanup Filter Vessels," Fifteenth Annual Meeting of the American Association for Aerosol Research, AAAR '96, Orlando, FL, October 14-18, 1996.

G. Ahmadi and Q. Chen, "Dispersion and Deposition of Particles in a Turbulent Pipe Flow with Sudden Expansion," Fifteenth Annual Meeting of the American Association for Aerosol Research, AAAR '96, Orlando, FL, October 14-18, 1996. 
M. Soltani and G. Ahmadi, "Trajectory Statistics of Charged Particle Deposition in a Directly Simulated Turbulent Channel Flow," Fifteenth Annual Meeting of the American Association for Aerosol Research, AAAR '96, Orlando, FL, October 14-18, 1996.

Z. Wong and G. Ahmadi, "Numerical Simulation of Curly Fiber Transport in Turbulent Flow," Fifteenth Annual Meeting of the American Association for Aerosol Research, AAAR '96, Orlando, FL, October 14-18, 1996.

G. Ahmadi, T. Chen, H. Ban and J. Stencel, "Air Flow and Particle Transport in an Electrostatic Coal/Ash Cleaning System," Proceedings of the Second International Symposium on Scale Modeling (ISSM-II), Lexington, Kentucky, June 23-27, 1997, pp. 315-325.

G. Ahmadi, K. Elliott and W. Kvasnak, "Granular Flow in a Couette Flow Device - An Experimental Study," Proceedings of the Second International Symposium on Scale Modeling (ISSM-II), Lexington, Kentucky, June 23-27, 1997, pp. 327-335.

G. Ahmadi and D.H. Smith, "Computational Modeling of Particle Transport and Deposition in Hot-Gas Cleanup Filter Vessels," Proceedings of the Second International Symposium on Scale Modeling (ISSM-II), Lexington, Kentucky, June 2327, 1997, 337-350.

G. Ahmadi, J. Cao and M. Massoudi, "Chute Flows of Granular Materials with Energy Dissipation," The Joint ASME/ASCE/SES Summer Meeting, McNU '97, Northwestern University, Chicago, IL June 29 - July 2, 1997.

G. Ahmadi, "Overview of Lagrangian - Eulerian Particle Transport and Deposition in Turbulent Flows," The Joint ASME/ASCE/SES Summer Meeting, McNU '97, Northwestern University, Chicago, IL June 29 - July 2, 1997.

G. Ahmadi and S. Abu-Zaid, "An Anisotropic Model for Dense Two-Phase Flows," The Joint ASME/ASCE/SES Summer Meeting, McNU '97, Northwestern University, Chicago, IL June 29 - July 2, 1997.

\section{Seminar and Lecture Presentations}

"Particle - Turbulence Interactions - Part I, Dilute Flows," Morgantown Energy Technology Center, U.S. Department of Energy, Morgantown, WV (September 13, 1995).

"Particle - Turbulence Interactions - Part II, Dense Flows," Morgantown Energy Technology Center, U.S. Department of Energy, Morgantown, WV (September 20, 1995).

"Modeling of Granular and Dense Two-Phase Flows," Department of Mechanical Engineering, University of Pittsburgh, Pittsburgh, PA (October 26, 1995). 
"Particles Transport and Deposition in Turbulent Flows," Department of Mechanical Engineering, West Virginia University, Morgantown, WV (November 29, 1995).

"Recent Advances in Computational Modeling of Particle Transport, Deposition and Resuspension," Center for Applied Energy Research, University of Kentucky, Lexington, KY (December 18, 1995).

"Computational Modeling of Particles Transport, Deposition and Resuspension in Industrial Systems," MEMC, St Louis, MO, (June 27, 1997).

"Some Ideas for Computational Modeling of Dilute and Dense Turbulent Two-Phase Flows," FLUENT, Lebanon, NH, (July 17, 1997).

"On Computational Modeling of Particles Transport and Deposition in Hot-Gas Filter Vessels," Federal Energy Technology Center, Morgantown, WV (August 6, 1997).

"Recent Advances in Particle Transport, Deposition and Removal," ASYST Technologies Inc., Fremont, CA (October 13, 1997). 